\title{
Health professionals' perceptions of pediatric patient safety culture
}

\author{
Perceção dos profissionais de saúde sobre a cultura de segurança do doente pediátrico \\ Percepción de los profesionales de la salud acerca de la cultura de seguridad del paciente \\ pediátrico
}

Ernestina Maria Batoca Silva*, Dora Lúcia Lopes Pedrosa**;

Andrea Patrícia Correia de Leça***; Daniel Marques Silva****

\begin{abstract}
Background: The safety culture of any organization holds special meaning for the patients, taxpayers, managers and care providers, and it is a phenomenon that can be assessed in its various dimensions.

Objective: To assess the health professionals' perceptions of the pediatric patient safety culture.

Methodology: A quantitative descriptive study was conducted using a non-probability sample of 258 health professionals working in pediatric and neonatal units of 2 Portuguese hospitals/hospital centers. The instrument is based on the Hospital Survey on Patient Safety Culture.

Results: Most professionals consider patient safety to be good or very good. The Teamwork Within Units dimension stood out positively, whereas Management Support for Patient Safety and Non-Punitive Response to Errors dimensions were considered problematic dimensions. More than 79\% of the professionals did not report any events/occurrences in the 12 months prior to data collection.

Conclusion: These data suggest that it is necessary to invest in a safety culture that promotes voluntary and non-punitive reporting of errors and adverse events.
\end{abstract}

Keywords: patient safety; quality of health care; medical errors; child health services

\section{Resumo}

Enquadramento: A cultura de segurança de qualquer organização tem especial significado para os doentes, pagadores, gestores e prestadores de cuidados, sendo um fenómeno passível de ser avaliado nas várias dimensões que integra.

Objetivo: Avaliar a cultura de segurança do doente pediátrico percecionada pelos profissionais de saúde.

Metodologia: Estudo quantitativo de cariz descritivo. A amostra é não probabilística, constituída por 258 profissionais de saúde a exercer funções em serviços pediátricos e neonatais de 2 hospitais/centros hospitalares portugueses. O instrumento baseia-se no Hospital Survey on Patient Safety Culture.

Resultados: A maioria dos profissionais considera a segurança do doente boa ou muito boa. A dimensão Trabalho em Equipa destacou-se pela positiva, sendo o Apoio à Segurança do Doente pela Gestão e Resposta ao Erro não Punitiva consideradas problemáticas. Mais de $79 \%$ dos profissionais não notificou eventos/ocorrências nos últimos 12 meses.

Conclusão: Estes dados sugerem ser necessário investir numa cultura de segurança que promova a notificação voluntária e não punitiva do erro e incidentes adversos.

Palavras-chave: segurança do paciente; qualidade da assistência à saúde; erros médicos; serviços de saúde da criança

\footnotetext{
* Ph.D., Professor, Health School of Viseu, 3500-843, Viseu, Portugal [ernestinabatoca@sapo.pt]. Contribution to the article: data analysis and discussion, article writing. Address for correspondence: Rua da Peça, $n^{\circ}$ 64, Esculca, 3500-843, Viseu, Portugal.

* MSc., RN, Child Health and Pediatrics, Maternity Hospital Dr. Daniel de Matos, Coimbra Hospital and University Center, 3030-165, Coimbra, Portugal [dora_pedrosa@ hotmail.com]. Contribution to the article: literature search, data collection, analysis and discussion; article writing.

***arure search, data collection, analysis and discussion; article writing. apcl@gmail.com]. Contribution to the article: literature search, data collection, analysis and discussion; article writing.

***** Ph.D., Coordinating Professor, Health School of Viseu, 3500-843, Viseu, Portugal [dsilva.essv@gmail. com].
}

\section{Resumen}

Marco contextual: La cultura de seguridad de cualquier organización tiene un significado especial para los pacientes, pagadores, administradores y cuidadores, y es un fenómeno sujeto a ser evaluado en las diversas dimensiones que integra. Objetivo: Evaluar la cultura de seguridad del paciente pediátrico percibida por los profesionales de la salud.

Metodología: Estudio cuantitativo de carácter descriptivo en una muestra no probabilística constituida por 258 profesionales de la salud de los servicios pediátricos y neonatales de 2 hospitales/centros hospitalarios portugueses. El instrumento se basa en la Hospital Survey on Patient Safety Culture.

Resultados: La mayoría de los profesionales considera que la seguridad de los usuarios es buena o muy buena. La dimensión Trabajo en Equipo destacó positivamente, mientras que el Apoyo a la Seguridad del Paciente por la Dirección y Respuesta al Error no Punitiva se consideraron problemáticas. Más del 79 \% de los profesionales no notificó acontecimientos/incidentes en los últimos 12 meses.

Conclusión: Estos datos sugieren que es necesario invertir en la concepción de una cultura de seguridad que promueva la notificación voluntaria y no punitiva del error y de los acontecimientos adversos.

Palabras clave: seguridad del paciente; calidad de la atención de la salud; errores médicos; servicios de salud del niño

Received for publication: 05.02 .15

Accepted for publication: 20.04 .16 


\section{Introduction}

Patient safety is recognized today as an extremely important component for the quality of health care, assuming a prominent role in the agenda of health and society. In addition to the raised general interest, it has a special meaning for patients, taxpayers, managers and care providers (Fragata, 2011).

In Portugal, the true dimension or consequences of healthcare-related safety risks are not known. However, it is estimated that 10 out of 100 hospital admissions face complications due to an error or incident. Despite the constant risk in every situation, safety breaches are more likely to occur in certain situations, such as in intensive care inpatients or pediatric patients (Fragata, 2011).

The development of a safety culture is a key aspect for improving the safety and quality of care (Weaver et al., 2013). As such, it is important to assess it with a view to identifying priority areas of intervention (Sorra \& Dyer, 2010).

Given the lack of studies on the safety of pediatric patients and since we believe that children deserve a differentiated attention, we found it appropriate to develop this study to assess the health professionals' perceptions of pediatric patient safety culture. This study aims to raise the awareness of health professionals to reflect on and adopt a pediatric patient safety culture toward the safety and quality of care provision.

\section{Background}

The concern with safety in health care has been gradually increasing, and it is currently considered by the international community as a serious public health problem (Direcção-Geral da Saúde, Departamento da Qualidade na Saúde, 2011).

Although there are no accurate data on the number of patients affected by an adverse event related to care provision in Portugal, based on the results of international studies, 10 out of 100 hospital admissions are estimated to be subjected to some type of error (Fragata, 2010). This is just an approximate number, but it is undeniable that the problem exists. For this reason, the Portuguese Ministry of Health has been showing a growing concern with patient safety, considering it as a priority area for health quality.
It is important to emphasize that the lack of patient safety can have an impact at various levels, with health care users being the first victims. Fortunately, around $2 / 3$ of all existing errors do not cause damage, $1 / 3$ causes minor damage, and only $5 \%$ causes severe and irreversible damage (Fragata, 2010). However, there are broader implications that must not be neglected, namely the loss of confidence in the health organizations and their professionals; less likelihood of achieving the expected/desired results; and the increase of direct and indirect costs, with a major impact on health economy (Fragata, 2010).

In view of the above, safety is clearly an issue that requires greater attention. It is understood that "the design of the system and of the organization have a major impact on safety", and that an investment should be made in the development of safer working models and environments capable of minimizing human error (Fragata, 2011, p. 53). In addition, since organizations are composed of people, the safety culture shared by professionals should be valued, being considered an essential element to improve the safety and quality of health care provision to the population (Weaver et al., 2013).

The safety culture of any organization is a complex multidimensional phenomenon. Taking into account the scope of the concept, there is no consensus as to its dimensions and the aspects to be considered for its development. However, some characteristics are recurrent in the literature, such as reporting of adverse events; systematic view of the error; learning from error; importance of communication; general concern with safety; importance of leadership; teamwork; evidence-based and patient-centered care; and the just culture, in which people are not punished by their errors, only violations are punished (Stavrianopoulos, 2012).

It is essential to acknowledge that all human systems are susceptible to errors and their inevitability and probability of occurrence is directly proportional to the complexity of the system itself (Fragata, 2010). The recognition of the inevitability of error should be combined with the development of a non-punitive system of reporting and analysis of adverse events, allowing for the proactive identification of latent threats and, consequently, the development of a learning culture rather than the apportionment of blame (Paese \& Sasso, 2013). 
Despite the lack of studies on safety of the pediatric patient, the existing data are worrying. Children, in their specificity, are believed to be more vulnerable to the occurrence of adverse events during hospitalization than adults. The high variability in the ages of hospitalized children, resulting in developmental differences, requires the constant adaptation of care providers.

Therefore, errors and adverse events in children vary greatly when compared to adults. Severe errors occur more often in critical care settings and adverse drug events are three times more frequent among children than among adults (American Academy of Pediatrics, 2011).

In addition to the increased risk of pediatric patients, the likelihood and severity of these incidents is also important in the event of prolonged admissions and/ or of hospitalization in intensive care units for being complex hospital environments (Fragata, 2011).

Another risk factor is the children's inability to often question the care being provided. Although the parents' presence during hospitalization is recommended since it contributes to the promotion of the child's health and well-being and the quality and safety of care (Sanders, 2014), the parents or guardians are often unable to be constantly present at their children's side, impeding an additional protection that would minimize the occurrence of some errors.

Muething et al. (2012) emphasized that adverse events are common in hospitalized children, increasing the length of hospital stay, the in-hospital mortality rate and the total costs.

Although safety culture is a variable that can be isolated, analyzed and changed, the studies performed within this scope in pediatric settings are virtually non-existent (Poley, Starre, Bos, Dijk, \& Tibboel, 2011).

\section{Research question}

What are the health professionals' perceptions of the pediatric patient safety culture?

\section{Methodology}

This is a quantitative descriptive study using a non-probability sample composed of 258 health professionals (technical assistants, operational assistants, nurses, physicians, diagnosis and therapy technicians, senior technicians) from two Portuguese hospitals/ hospital centers. The sample in hospital 1 (H1) is composed of 167 professionals from the pediatric and neonatal inpatient units, whereas the sample in hospital 2 (H2) is composed of 91 professionals working in the inpatient, emergency, pediatric and neonatal intensive care units.

The data collection instrument used was a self-administered questionnaire based on the Hospital Survey on Patient Safety Culture of the Agency for Healthcare Research and Quality, which was translated and validated for the Portuguese population (Eiras, Escoval, Grillo, \& Silva-Fortes, 2014). Twelve dimensions of the patient safety culture are considered, including: Teamwork Within Units; Supervisor/Manager Expectations and Actions Promoting Patient Safety; Management Support for Patient Safety; Organizational Learning - Continuous Improvement; Overall Perceptions of Patient Safety; Feedback and Communication about Error; Communication Openness; Frequency of Events Reported; Teamwork Across Units; Staffing; Handoffs and Transitions; and Non-Punitive Response to Errors; as well as two single-item variables: patient safety grade, and number of events reported in the past 12 months.

Each of the questionnaire items is scored on a 5-point Likert scale, where 1 corresponds to strongly disagree or never and 5 corresponds to strongly agree or always. In accordance with the recommendations from the authors of the original scale, the results were analyzed and interpreted after recoding the scale from five to three levels, in which 1 corresponds to the total negative responses (includes point 1 and 2 of the above-mentioned scale), 2 corresponds to the neutral responses, and 3 corresponds to the total of positive responses (aggregating points 4 and 5).

The results were grouped by dimensions, translating the professionals' perceptions through percentages of positive, neutral and negative responses. The analysis was performed based on the composite frequency of answers that translates the percentage of positive answers to the set of items for each dimension. Based on these scores, it is possible to identify the strong and weak factors and indicators concerning patient safety culture. A factor was classified as strong based on the criterion established by the Agency for 
Healthcare Research and Quality, which corresponds to a mean percentage of positive answers higher than or equal to $75 \%$. Conversely, if the mean percentage of positive answers is equal to or lower than $50 \%$, this factor or area is considered to be weak, suggesting a safety culture with negative aspects and in need for improvement.

Each questionnaire was validated taking into account the authors' recommendations. The following questionnaires were excluded: those in which less than half of the items were filled out; those in which no section was completely filled out; and those in which all items were similarly filled out (except for section $\mathrm{E}$ ).

The reliability of the safety culture assessment questionnaire was analyzed through the internal consistency of its dimensions. In H1, the results of the Cronbach's alpha coefficients indicated scores ranging from 0.60 in the Staffing dimension to 0.89 in the Frequency of Events Reported dimension, with a score of 0.91 for the total scale. In $\mathrm{H} 2$, we found scores ranging from 0.31 in the Overall Perceptions of Patient Safety dimension and 0.85 in the Frequency of Events Reported dimension, with a score of 0.86 for the total scale.

Based on these results, the questionnaire is this study showed good internal reliability, which is similar to that observed in previous studies, namely those developed for the validation to the Portuguese sociocultural context.

Data were analyzed using the Statistical Package for the Social Sciences (SPSS $®$ ), version 22.0, and the significance level was set at 5\% ( $p=.05)$.

The ethical principles were ensured during the study. We requested permission to both the author to use the data collection tool and the board of directors of the hospitals/hospital centers to conduct the study, which was approved by the Ethics Committees. The researcher team delivered the questionnaires to be distributed among the professionals to the head nurses and directors of services. Each completed questionnaire was placed in an envelope without identification, thus ensuring the health professionals' anonymity.

The respondents gave their consent and their participation was voluntary. Data were collected between June and October 2014.

\section{Results}

The sample selected in both hospital units was mainly composed of female professionals $(86.8 \%$ in $\mathrm{H} 2$ and $88.6 \%$ in $\mathrm{H} 1$ ). Both in $\mathrm{H} 1$ and in $\mathrm{H} 2,64.7 \%$ and $67 \%$ of the respondents, respectively, were nurses. Virtually all respondents (96.7\% in $\mathrm{H} 2$ and $94 \%$ in $\mathrm{H} 1$ ) stated that they usually have direct contact with the patients in their professional practice.

With regard to the time of professional experience in that service/unit, in pediatrics and in the institution, most professionals in $\mathrm{H} 1$ had been working in each of those areas for less than 5 years $(42.5 \%, 25.1 \%$ and $21.6 \%$, respectively). On the other hand, $30.8 \%$ of the respondents in $\mathrm{H} 2$ had been working in that service/ unit between 3 and 7 years, 31.9\% had been working in pediatrics between 3 and 7 years, and 34.1\% had been working in the institution between 8 and 12 years.

When asked about the frequency of training on patient safety and risk management, $72.5 \%$ of the professionals in $\mathrm{H} 2$ and $56.3 \%$ in $\mathrm{H} 1$ had already attended training and 94.5\% in $\mathrm{H} 2$ and 94\% in $\mathrm{H} 1$ showed interest in receiving training in that area, if possible.

In order to answer the research question What are the health professionals' perceptions of the pediatric patient safety culture?, and after analyzing the 12 dimensions of the safety culture (Table 1), we found that, of all the 12 dimensions, the Teamwork Within Units dimension obtained the highest score in both hospital units. In addition, the Organizational Learning - Continuous Improvement and Feedback and Communication about Error dimensions obtained a mean percentage of positive answers $>75 \%$ in $\mathrm{H} 2$, thus being considered to be strong dimensions (Figure 1).

On the other hand, health professionals of both hospital units considered the Management Support for Patient Safety and the Non-Punitive Response to Errors dimensions to be weak. In H1, the Frequency of Events Reported and Staffing dimensions also had a mean percentage of positive answers $\leq 50 \%$.

As regards the remaining assessed dimensions, despite not being considered weak, they should be carefully analyzed in the long term so that they may become strong aspects of the institution. 
Table 1

Safety culture dimensions and respective short form
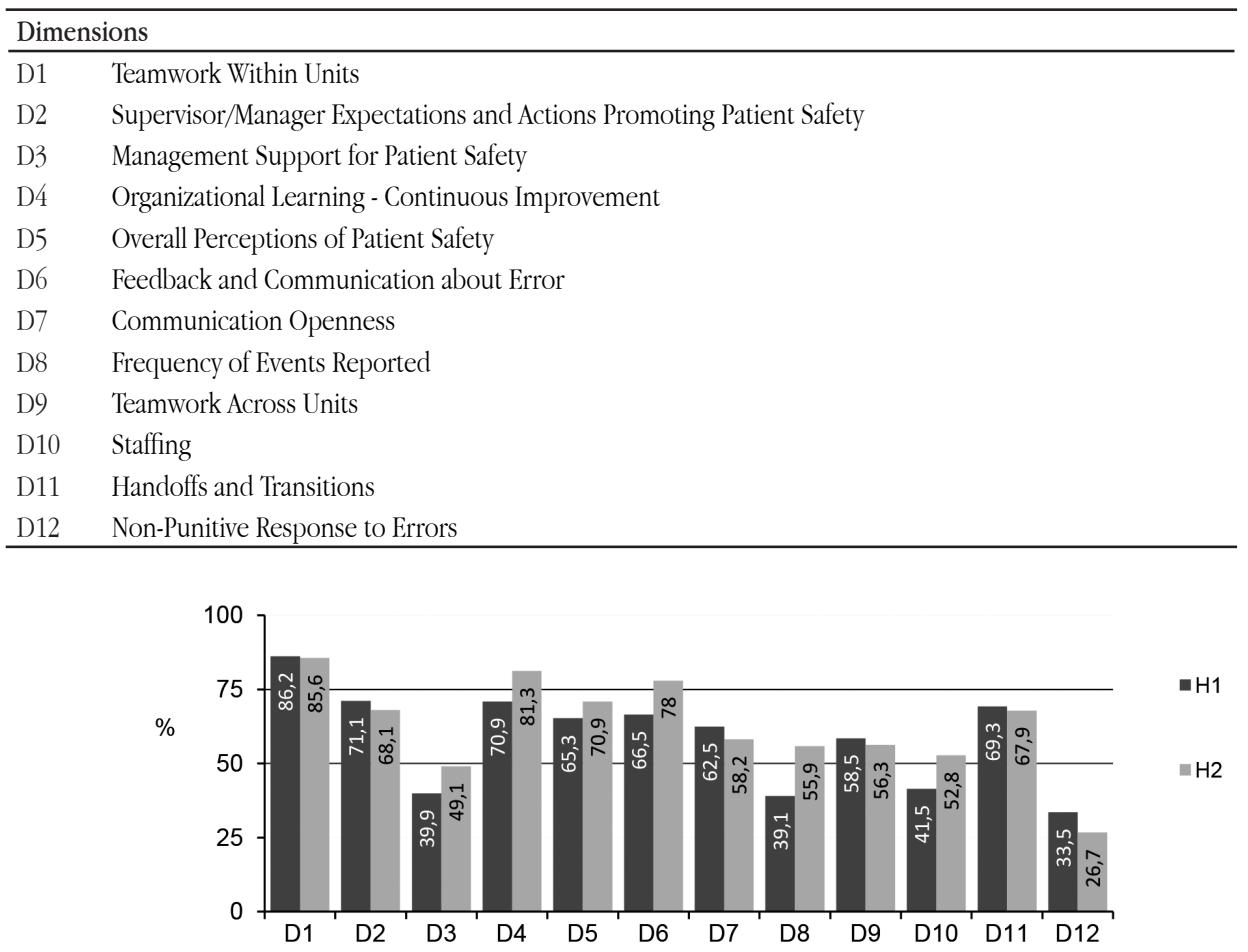

Figure 1. Mean percentage of positive answers to each of the 12 safety culture dimensions under analysis.

By analyzing the specific patient safety grade assigned by the professionals to their service, we found that most respondents (68.9\% in $\mathrm{H} 1$ and $58.2 \%$ in $\mathrm{H} 2$ ) considered it to be very good.

As regards the reporting experience, we observed that more than $79 \%$ of the professionals in $\mathrm{H} 1$ and $84.6 \%$ in $\mathrm{H} 2$ did not report any event/occurrence in the past 12 months.

\section{Discussion}

We found that, both in $\mathrm{H} 1$ and in $\mathrm{H} 2$, nursing is the most represented professional class and that most professionals were women, which was expected considering the traditional predominance of women in the nursing profession.

The professionals assigned a very positive patient safety grade to their service. In H1, we found that $68.9 \%$ of them consider it to be very good and that $12.6 \%$ even feel that the patient safety grade in their service is excellent. These data are significantly better than those found by Peralta (2012), Sousa (2013) and Gomes (2012), where $42.3 \%, 40.6 \%$ and $38.3 \%$ of the professionals, respectively, consider that the service where they work has an acceptable patient safety grade. In H2, the Patient Safety Grade is perceived by most professionals (58.2\%) as being very good, which is consistent with the majority of Portuguese studies, in particular those of the Directorate-General for Health, Department of Quality in Health (2011) with 45\%, Fernandes and Queirós (2011) with 46\%, Gomes (2012) with 53\%, Peralta (2012) with 51\% and Pimenta (2013) with 60\%.

The results should be carefully compared and their generalization should be avoided. However, based on these results, and since our study was only conducted in pediatric settings, we believe that the professionals' perceptions of the pediatric patient safety grade is higher. In the same line, when comparing studies conducted in neonatal intensive care units and adult intensive care units, Profit et al. (2012) concluded that the scores on safety culture were higher in neonatal units. 
The results obtained concerning the Overall Perceptions of Patient Safety dimension demonstrate some agreement with the opinion on the patient safety grade assigned by the professionals to their service. Unlike the results obtained by Gomes (2012) and Sousa (2013), who did not reach $50 \%$ of mean positive answers, our results (70.9\% in $\mathrm{H} 2$ and $65.3 \%$ in $\mathrm{H} 1$ ) are identical to those of the North-American study (63\%) performed by Mardon, Khanna, Sorra, Dyer, and Famolaro (2010). One of the ways of focusing on safety is to identify the perceptions of the safety climate. These show how employees perceive patient safety based on their perceptions of their leaders' level of commitment toward safety, priority given to safety and dissemination of safety information. Therefore, the simple fact that the professionals' perceptions of patient safety are positive is a good starting point for improving patient safety.

Among the assessed dimensions, the health professionals positively highlighted the Teamwork Within Units dimension. In all of the studies consulted, this dimension stands out (Mardon et al., 2010; Fernandes \& Queirós, 2011; Direcção-Geral da Saúde, Departamento da Qualidade na Saúde, 2011; Gomes, 2012; Peralta, 2012; Pimenta, 2013; Sousa, 2013), but none of them obtained such a high percentage. Teamwork is essential for the quality of healthcare provision since it generates safety, in the sense that "it substantially reduces both the number of errors and the potential for error in a severe situation" (Fragata, 2010, p. 206). In relation to the weak dimensions, the Management Support for Patient Safety dimension was one of the dimensions with the lowest mean percentage of positive answers. Similarly to our study, several Portuguese researchers obtained less than 50\% of positive answers, namely Sousa (2013) with 24\%, Gomes (2012) with 28\%, DGS (Direcção-Geral da Saúde, Departamento da Qualidade na Saúde, 2011) with 48\% and Fernandes and Queirós (2011) with 44\%. In a study carried out exclusively in neonatal intensive care units, Profit et al. (2012) also found perceptions of lack of support from hospital management. These results suggest the need for hospital management to reveal the activities being in fact developed for the promotion of the safety and quality of care provision. Despite the current financial constraints that hamper the management of any public organization, we believe that, although some projects have been developed and implemented, their dissemination among health professionals has not been effective. Management support for patient safety is essential to promote a climate of trust and the feeling that people are working toward a common goal, which undoubtedly influences the professional's motivation and availability (Profit et al., 2012).

In H1, contrarily to what happens in H2, Staffing was also perceived to be a weak dimension (41.5\%). The hiring of temporary professionals did not emerge as a concern. However, most health professionals believe that they work more hours per shift than what would be desirable and only $44.9 \%$ of them consider that there are enough human resources for the amount of work performed. Given that staffing is, undoubtedly, a factor that contributes to the safety and quality of care, it is essential to reflect on this matter and develop strategies to address this issue.

The analysis of the data collected in $\mathrm{H} 1$ and $\mathrm{H} 2$ revealed another worrying factor: the Frequency of Events Reported, which is one of the dimensions with the lowest mean percentage of positive answers in $\mathrm{H1}$ (39.1\%), as in the studies carried out by Peralta (2012), Sousa (2013) and Fernandes and Queirós (2011). Unlike some of the results obtained in Portugal, a study conducted in the United States of America with a sample composed of more than 56,000 professionals showed a significantly higher percentage for this dimension: 60\% (Mardon et al., 2010). In line with what was previously mentioned, we also found that most of the health professionals (79.6\% in $\mathrm{H} 1$ and $84.6 \%$ in $\mathrm{H} 2$ ) did not report any event/occurrence in the past 12 months.

The studies carried out by Fernandes and Queirós (2011), DGS (Direcção-Geral da Saúde, Departamento da Qualidade na Saúde, 2011), Gomes (2012), Peralta (2012), Sousa (2013) and Pimenta (2013) also found low reporting rates and that a large percentage of respondents did not report any event in the 12 months prior to data collection, corresponding to $80 \%, 73 \%$, $76.7 \%, 68.6 \%, 68.7 \%$ and $68 \%$ of the professionals, respectively.

These data are consistent with the information provided by the DGS (Direcção-Geral da Saúde, 2014), which found only 190 reports by health professionals using the SNNIEA/NOTIFICA system in the first half of 2014. As a highly complex area, health care is susceptible to the occurrence of errors (Eiras et al., 2014), hence we believe that these figures do not reflect the national reality. 
Underreporting is indeed a problem with multiple causes. Sorra and Dyer (2010) pointed out the fear of reprisals and the lack of feedback after errors as the main obstacles to error reporting, which contribute to a perception of uselessness.

The Non-Punitive Response to Errors is the most challenging dimension among all dimensions (33.5\% in $\mathrm{H} 1$ and $26.7 \%$ at $\mathrm{H} 2$ ), similarly to what was observed in other studies (Mardon et al., 2010; Fernandes \& Queirós, 2011; Direcção-Geral da Saúde, Departamento da Qualidade na Saúde, 2011; Gomes, 2012; Peralta, 2012; Pimenta, 2013; Sousa, 2013). Professionals fear that their errors will be recorded in their personal files. Thus, it is necessary to change mentalities and ensure the anonymity of the reports of incidents and adverse events, while safeguarding the legal safety of the information and those involved (Sousa, 2013). These results suggest the existence of a culture of apportionment of blame to the detriment of a just culture, which advocates constant learning and improvement toward patient safety.

The existence of punitive and stigmatizing responses contributes to underreporting which, in turn, leads to neglecting valuable information about the errors, hampering their analysis and the implementation of corrective measures. Although the study by Fragata (2010) concluded that about $2 / 3$ of all existing errors do not cause damage, this fact is not enough to motivate professionals to report errors and reduce the fear of punishment associated with it. It is urgent to invest in this area. Changing mentalities is a slow, but possible, process. A guilt-free environment should be promoted, especially because the error is inherent to human condition. Each individual, regardless of profession, age, experience or professional competence, may make a mistake at any time. The key is to analyze each of the incidents, learn from them and use that knowledge to minimize the occurrence of future events (Paese \& Sasso, 2013).

Although we analyzed each dimension individually, it is not difficult to understand that safety culture should be seen in an integrative way, considering that its multiple dimensions have the ability to influence each other. If there is a perception of the punitive response to error, then the reporting rate of adverse events and incidents is expected to be low.

The investment in vocational training is determinant to promote a safety culture, taking advantage of the fact that most of the surveyed professionals would be interested in attending training on safety and risk management. Based on data analysis, our suggestion is to initially focus on issues related to error and the importance of reporting, encouraging the exchange of information within the services. It is essential to gradually train, inform and deconstruct the idea of apportionment of blame.

We are aware that this study had some limitations, and, for this reason, the results should be carefully interpreted and generalized. The first limitation relates to the lack of studies on pediatric patient safety culture, which hampered the discussion of results. Another relevant limitation relates to the type of sampling and number of subjects, because if the sample is not representative of the population, the results cannot be generalized.

\section{Conclusion}

Patient safety is an ethical imperative and an increasing concern for professionals and health care providers. Assessing the safety culture is an essential tool to improving the quality of health care.

In view of the objective set out for this study, we found that the Teamwork Within Units was the strongest dimension, even standing out from results obtained in other national and international studies. The Organizational Learning - Continuous Improvement and Feedback and Communication about Error dimensions were also considered as strong aspects by the professionals of $\mathrm{H} 2$.

Data analysis showed that the Management Support for Patient Safety and Non-Punitive Response to Errors were the weakest dimensions in both hospital units, thus requiring priority intervention.

In relation to the patient safety grade in their service, most professionals $(81.5 \%$ in $\mathrm{H} 1$ and $64.8 \%$ in $\mathrm{H} 2$ ) believe that it is very good to excellent, although more than $79 \%$ of them did not report any incident in the 12 months prior to data collection.

Underreporting is a reality in these institutions, as it is across many Portuguese hospitals. Considering the importance of reporting incidents in the process of learning from error and the negative perception of the Non-Punitive Response to Errors dimension, we argue that it is urgent to develop a patient safety policy that promotes voluntary and non-punitive reporting of all incidents with the consequent identification of 
errors and implementation of corrective measures to prevent errors from being repeated. However, this is only the first step. A subsequent investment should be made in other areas, namely in studies about the damage caused by errors and their dissemination among professionals.

We found several differences between this study and the reviewed literature, namely studies conducted in other countries: the sociocultural context, sample size and type of sampling, among others. Nevertheless, and despite the expectable result differences, it is possible to identify several similarities in the results, with most of them being equivalent. Since the strongest and weakest dimensions of Patient Safety Culture are similar, the Intervention Needs are also similar. Changing the culture is never an easy process, but we believe that it is possible. If an investment is made in vocational training and in the implementation of simple measures, it is possible to build a safer hospital environment, benefiting patients, professionals and institutions.

\section{References}

American Academy of Pediatrics. (2011). Principles of pediatric patient safety: Reducing harm due to medical care. Pediatrics, 127(6), 1199-1212. doi: 10.1542/peds.2011-0967

Direcção-Geral da Saúde, Departamento da Qualidade na Saúde. (2011). Avaliação da cultura de segurança do doente numa amostra de hospitais portugueses: Resultados do estudo piloto. Lisboa, Portugal: Autor.

Direcção-Geral da Saúde. (2014). Informação da Direcção-Geral da Saúde n.․ 002/2014 de 25/02/2014: Relatório de progresso de monitorização do SNNIEA 2013. Lisboa, Portugal: Autor.

Eiras, M., Escoval, A., Grillo, I. M., \& Silva-Fortes, C. (2014). The hospital survey on patient safety culture in Portuguese hospitals: Instrument validity and reliability. International Journal of Health Care Quality Assurance, 27(2), 111-122. doi: 10.1108/IJHCQA-07-2012-0072

Fernandes, A., \& Queirós, P. (2011). Cultura de segurança do doente percecionada por enfermeiros em hospitais distritais portugueses. Revista de Enfermagem Referência, 3(4), 3748. doi: 10.12707/RIII1040

Fragata, J. (2010). A segurança dos doentes: Indicador de qualidade em saúde. Revista Portuguesa de Clinica Geral, 26(6), 564-570

Fragata, J. (2011). Segurança dos doentes: Uma abordagem prática. Lisboa, Portugal: Lidel
Gomes, M. J. (2012). Cultura de segurança do doente no bloco operatório (unpublished master's thesis). Escola Superior de Enfermagem de Coimbra, Portugal.

Mardon, R. E., Khanna, K., Sorra, J., Dyer, N., \& Famolaro, T. (2010). Exploring relationships between hospital patient safety culture and adverse events. Journal of Patient Safety, 6(4), 226-232. doi: 10.1097/PTS.0b013e3181fd1a00

Muething, S., Goudie, A., Schoettker, P., Donnely, P., Goodfriend, M., Bracke, T., ... Kotagal, U. (2012). Quality improvement initiative to reduce serious safety events and improve patient safety culture. Pediatrics, 130(2), e423-e431. doi: 10.1542/ peds.2011-3566

Paese, F., \& Sasso, G. T. (2013). Cultura de segurança do paciente na atenção primária à saúde. Texto $\mathcal{G}$ Contexto Enfermagem, 22(2), 302-310. doi: 10.1590/S0104-07072013000200005

Peralta, T. J. (2012). Segurança do doente: Perspectivas dos profissionais de um hospital da região centro (unpublished master's thesis). Escola Superior de Enfermagem de Coimbra, Portugal.

Pimenta, L. C. (2013). Avaliação da cultura de segurança do doente e propostas de melhoria (master's thesis). Escola Superior de Tecnologia da Saúde de Lisboa/Escola Superior de Saúde da Universidade do Algarve, Portugal.

Poley, M. J., Starre, C., Bos, A, Dijk, M., \& Tibboel, D. (2011). Patient safety culture in a Dutch pediatric surgical intensive care unit: An evaluation using the safety attitudes questionnaire. Pediatric Critical Care Medicine, 12(6), e310-e316. doi: 10.1097/PCC.0b013e318220afca

Profit, J., Etchegaray, J., Peterson, L., Sexton, J., Hysong, S., Mei, M., \& Thomas. E. (2012). The safety attitudes questionnaire as a tool for benchmarking safety culture in the NICU. Archives of disease in childhood. Fetal and neonatal edition, 97(2), 127-132. doi: 10.1136/archdischild-2011-300612

Sanders, J. (2014). Cuidados centrados na família em situações de doença e hospitalização. In M. J. Hockenberry \& D. Wilson (Eds.), Wong: Enfermagem da criança e do adolescente ( $9^{\mathrm{a}}$ ed., Vol. 2, pp. 1025-1060). Loures, Portugal: Lusociência.

Sorra, J., \& Dyer, N. (2010). Multilevel psychometric properties of the AHRQ hospital survey on patient safety culture. BMC Health Services Research, 10(199), 1-13. doi: 10.1186/14726963-10-199

Sousa, A. M. (2013). Avaliação da cultura de segurança do doente num centro bospitalar da região centro (master's thesis). Universidade de Coimbra, Portugal.

Stavrianopoulos, T. (2012). The development of patient safety culture. Health Science Journal, 6(2), 201-211.

Weaver, S. J., Lubomksi, L. H., Wilson, R. F., Pfoh, E. R., Martinez, K. A., \& Dy, S. M. (2013). Promoting a culture of safety as a patient safety strategy: A systematic review. Annals of Internal Medicine, 158 (5 Part 2), 369-374. doi: 10.7326/00034819-158-5-201303051-00002 

